The Japanese Red Cross, too, has sent out a medical team. It has been assigned to the Paklay area, where it is responsible for the dispensary, examinations in the villages and a vaccination campaign.

Before long, a fourth medical team, set up by the British Red Cross and the French Red Cross, will be carrying out a similar mission in the Seno area, province of Savannakhet.

\title{
REAPPRAISAL OF THE ROLE OF THE RED CROSS
}

In 1970 the Standing Commission of the International Red Cross asked the ICRC and the League to make a study of problems relating to "a reassessment of the role of the International Red Cross in the light of present conditions". The League Board of Governors, meeting in Mexico City in October 1971, adopted a resolution which authorized the appointment of a sub-committee for that purpose, and expressed the hope that the study might in due course be linked to that already started by the ICRC. This was done under an agreement subsequently reached by the two international Red Cross institutions. ${ }^{1}$ The memorandum of understanding drawn up on that occasion embodied the following terms:

1. A Joint Committee shall be established with the following membership:

- 3 representatives appointed by the ICRC

- 1 representative appointed by the Henry Dunant Institute

- 4 representatives appointed by the League

The Presidents and the Secretaries General of the ICRC and the League or their respective representatives have the right to attend meetings of the Joint Committee.

${ }^{1}$ See International Review, January 1973. 
2. The League appoints one of its representatives Chairman and the ICRC appoints one of its representatives ViceChairman.

In case of the Chairman's absence, the Vice-Chairman shall preside at meetings of the Joint Committee.

3. The Joint Committee is responsible for the implementation of the Study and for its financing. The Joint Committee approves the Research Design and the budget for the Study. It appoints the Director and decides on his terms of reference.

4. The Director of the Study reports to the Chairman and/or to the Vice-Chairman on all matters concerning the implementation of his mandate.

Between the sessions of the Joint Committee the Chairman and/or the Vice-Chairman in consultation with each other may issue all necessary instructions to the Director of the Study in accordance with this understanding and the terms of reference of the Director.

5. In order to secure the necessary means the Joint Committee is entitled to approach selected charitable Foundations and National Red Cross Societies. If the Joint Committee finds it necessary to approach other sources of financing it must obtain the consent of the competent bodies of the ICRC and the League.

6. The Secretariat of the Study is established in Geneva outside the Secretariats of the ICRC and the League.

7. When the Joint Committee has completed its tasks it submits the report of the Study Director simultaneously to the competent bodies of the ICRC and the League.

The Joint Committee may present its own conclusions and recommendations.

8. The arrangements set out in this memorandum will take effect when it has been approved by the competent bodies of the ICRC and the League. At the same time the mandate of the Sub-Committee which was appointed by the Committee of the Chairman and Vice-Chairmen of the League according to the above-mentioned resolution of the Board of Governors will expire. 
The Chairman of the Joint Committee is Mr. Kai Warras, Secretary General of the Finnish Red Cross, and the Vice-Chairman Mr. Roger Gallopin, a member of the ICRC. Mr. Donald Tansley was appointed Study Director as from 1 February 1973. He established offices separate from those of the League and the ICRC and outlined future plans including the following preliminary steps:

1. Rapid completion of basic documents, the work of compiling, classifying and appraising the main reference documents having already been undertaken by the Study Secretariat in 1972.

2. Convening of a meeting of several members of the technical staff of National Societies that have already begun or ended an analysis of their own position.

3. A meeting of the Joint Committee for preliminary discussion on the conduct of the Study and on the Research Design submitted by the Director.

The meeting provided for under point 2 , for consultations with the planning experts of National Societies, was held in Geneva from 27 to 29 March 1973. It enabled fifteen experts belonging to thirteen Societies from four continents to give their views on the study for the reappraisal of the role of the Red Cross. The experts who took part in the proceedings devoted their efforts, as did other experts, to long-term planning in the Red Cross. Their National Societies are already engaged in a reappraisal of their own activities.

Representatives of the League of Red Cross Societies, the International Committee of the Red Cross and the Henry Dunant Institute and members of the Study Secretariat attended the proceedings.

The principal aim of the consultations was to help the Study Director establish priorities and the final Research Design, a task to which he will devote the next two or three years. Mr. Tansley was particularly anxious to take advantage of the experience acquired by National Societies already engaged in similar tasks and to benefit by advice and suggestions from national experts.

Discussions covered the universality, meaning and relevance of Red Cross values, the image and status of the Red Cross, the 


\section{IN THE RED Cross World}

role of youth in the Red Cross and, lastly, Red Cross participation in all aspects of the protection and improvement of the environment. In the broad discussion, Mr. Tansley referred to some of the suggestions made by the working groups and reminded the meeting of matters which in his opinion should come first in the study, particularly the importance of tasks performed by volunteers and the historic evolution of the functions and duties of the Red Cross in relation to other humanitarian organizations.

The National Societies of the following countries were represented at the meeting: Australia, Canada, Denmark, Finland, France, German Democratic Republic, Federal Republic of Germany, Norway, Peru, Poland, Romania, Spain and Switzerland.

The first meeting of the Joint Committee (point 3) was held in Geneva on 10 April 1973. The agenda items were the following:

1. Establishment of Joint Committee

2. Joint Committee's approval of Study Director's terms of reference

3. Report on the period starting 1 January 1973

4. Study Director's report on his activity and Research Design

5. The Financing of the Study

6. Confirmation of arrangements under which the League is responsible for financial and personnel questions

7. Second meeting of the Joint Committee when the Director has revised the Research Design, which will then be submitted to the Joint Committee for examination also of its financial repercussions. 